\title{
Determinants of early initiation of breastfeeding in Papua New Guinea: a population-based study using the 2016- 2018 demographic and health survey data
}

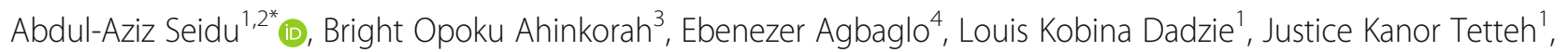
Edward Kwabena Ameyaw ${ }^{3}$, Tarif Salihu ${ }^{1}$ and Sanni Yaya ${ }^{5,6}$

\begin{abstract}
Background: Initiation of breastfeeding after birth comes with a wide range of benefits to the child. For example, it provides the child with all essential nutrients needed for survival within the first six months of birth. This study sought to determine the prevalence and factors associated with early initiation of breastfeeding (EIB) in Papua New Guinea.

Methods: We utilized the Demographic and Health Survey data of 3198 childbearing women in Papua New Guinea. We employed descriptive and binary logistic regression analyses. We presented the results as Crude Odds Ratios (COR) and Adjusted Odds Ratios (AOR), with 95\% confidence intervals (CI) signifying level of precision. Level of statistical significance was set at $p<0.05$.

Results: Women aged 20-29 [AOR $=1.583, \mathrm{Cl}=1.147-2.185]$ and those aged $30+[\mathrm{AOR}=1.631, \mathrm{Cl}=1.140-2.335]$ had higher odds of EIB, compared to those aged 15-19. Women from the Islands region had lower odds [AOR =0.690, $\mathrm{Cl}=0.565-0.842]$ of EIB, compared to those in Southern region. Women who delivered through caesarean section had

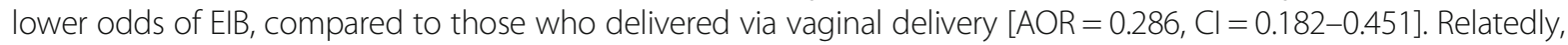
women who delivered in hospitals had lower odds of EIB [AOR $=0.752, \mathrm{Cl}=0.624-0.905]$, compared to those who delivered at home. Women who practiced skin-to-skin contact with the baby $[A O R=1.640, \mathrm{Cl}=1.385-1.942]$ had higher odds of EIB, compared to those who did not. Women who read newspaper or magazine at least once a week had lower odds of EIB [AOR $=0.781, \mathrm{Cl}=0.619-0.986]$, compared to those who did not read newspaper at all.

\footnotetext{
* Correspondence: abdul-aziz.seidu@stu.ucc.edu.gh

'Department of Population and Health, University of Cape Coast, Cape Coast, Ghana

${ }^{2}$ College of Public Health, Medical and Veterinary Sciences, James Cook University, Townsville, Queensland, Australia

Full list of author information is available at the end of the article
}

(c) The Author(s). 2020 Open Access This article is licensed under a Creative Commons Attribution 4.0 International License, which permits use, sharing, adaptation, distribution and reproduction in any medium or format, as long as you give appropriate credit to the original author(s) and the source, provide a link to the Creative Commons licence, and indicate if changes were made. The images or other third party material in this article are included in the article's Creative Commons licence, unless indicated otherwise in a credit line to the material. If material is not included in the article's Creative Commons licence and your intended use is not permitted by statutory regulation or exceeds the permitted use, you will need to obtain permission directly from the copyright holder. To view a copy of this licence, visit http://creativecommons.org/licenses/by/4.0/ The Creative Commons Public Domain Dedication waiver (http://creativecommons.org/publicdomain/zero/1.0/) applies to the data made available in this article, unless otherwise stated in a credit line to the data. 


\begin{abstract}
(Continued from previous page)
Conclusion: The prevalence of EIB in Papua New Guinea was relatively high (60\%). The factors associated with ElB are age of the women, region of residence, mode of delivery, place of delivery, practice of skin-to-skin contact with the baby, and exposure to mass media (newspaper). To increase EIB in Papua New Guinea, these factors ought to be considered in the implementation of policies and measures to strengthen existing policies. Health providers should educate mothers on the importance of EIB.
\end{abstract}

Keywords: Breastfeeding, Early initiation of breastfeeding, Newborn health, Papua New Guinea, Public health, Global health

\section{Background}

Early initiation of breastfeeding (EIB) is noted to come with a wide range of benefits to the child [1]. In the first place, it provides the child with all essential nutrients needed for survival within the first six months of birth [2]. Research suggests that EIB supplies the child with immunoglobin, which boosts the child's immune system and promotes the growth and development of the child [3]. Besides, globally, breastfeeding helps to save the lives of about $22 \%$ of children who die neonatally of diseases such as diarrhoea, meningitis [4], and pneumonia $[5,6]$. It has also been noted that EIB creates some form of bonding between the mother and child, which is necessary for the child's development [7]. On the other hand, breastfeeding, when delayed, leads to high prevalence of infant mortality $[8,9]$.

In view of the benefits of early breastfeeding, the World Health Organization (WHO) recommends that it should be initiated within the first hour of birth and this is termed as Early Initiation of Breastfeeding (EIB) [10]. EIB has seen much support from national and international bodies [11]. Despite this, over the years, there have not been any significant improvement in EIB globally [12]. Globally, less than half of newborns are breastfed within the first hour, and even in 2017, only $22 \%$ of all newborns were breastfed in the first hour of birth. In East Asia and the Pacific, only 32\% of newborns meet the WHO's recommendation of EIB [13]. In Papua New Guinea, the attempt by the government to protect breastfeeding through the passing of the Baby Food Supplies (Control) Act 1977 has yielded little results [8]. While nationally representative information on determinants of EIB is scarce in Papua New Guinea, studies by Kuzma [8] and Goris et al. [14] indicate a prevalence of $69 \%$ and $36.1 \%$ in rural and isolated communities in Gulf Province and Madang Province, respectively.

Studies abound on child breastfeeding practices, with focus on Bangladesh [15, 16], Ethiopia [17-20], Nepal [21], Niger [22], Nigeria [23], Saudi Arabia [24, 25], Tanzania [26], Uganda [27], and Zimbabwe [28, 29]. Such research have principally focused on trends of timely initiation of breastfeeding [30], predictors of delayed initiation of breastfeeding $[25,27]$ and determinants of EIB [17-22, 26]. Age, religion [30], parity [28], mother's educational status [21], and geographical region of residence $[16,19]$ have been reported to be associated with EIB. In Papua New Guinea, generally, while there are few studies on infant feeding practices [8], such studies did not consider its associated factors. Papua New Guinea records an overwhelmingly high percentage of child deaths in the Pacific. Also, this lack of research on the subject in the context of Papua New Guinea means a lack of empirical basis for policy interventions and programs aimed at improving EIB which can reduce child deaths. The present study, therefore, aimed at investigating the prevalence and determinants of EIB in Papua New Guinea. Findings from the study will provide target areas for interventions and programs aimed at improving EIB in Papua New Guinea and go a long way to reduce child deaths in the country.

\section{Methods}

\section{Data source and sample}

The data used for this study forms part of the 20162018 Papua New Guinea Demographic and Health Survey (PDHS), which was collected from October 2016 to December 2018. A two-stage stratified sampling procedure was used to sample census units (CUs) from each stratum. Stage one involved the selection of 800 CUs. This was done through probability proportional to $\mathrm{CU}$ size [31]. The second stage saw the systematic selection of 24 households from each cluster through probability sampling, and this yielded a total of 19,200 households. For this study, we focused on women who had given birth 2 years prior to the survey, and such women numbered 3198, all of which had complete information on the variables the present study was interested in [31]. Details of the methodology, pretesting, training of field workers, the sampling design, and selection are available in the PDHS final report, accessible via the following link: https://dhsprogram.com/publications/publicationfr364-dhs-final-reports.cfm.

\section{Study variables Outcome variable}

The outcome variable was EIB. In the PDHS woman's questionnaire, mothers were asked "How long after birth 
did you first put (NAME) to the breast?" Responses were recorded in number of hours or days [19, 32]. Our outcome variable "EIB" was defined as initiation of breastfeeding within $1 \mathrm{~h}$ of birth and was expressed as a dichotomous variable with category 1 for initiation of breastfeeding within $1 \mathrm{~h}$ (early) and category 0 for initiation of breastfeeding after $1 \mathrm{~h}$ (late). This indicator was self-reported by mothers.

\section{Independent variables}

Fifteen independent variables that were theoretically and empirically related to EIB were considered in this study $[8,19,30,32,33]$. These are mother's age at childbirth, mother's education, mother's religion, birth order of child, number of ANC visits, region, residence, wealth, mode of delivery, place of delivery, child size at birth, skin-to-skin contact, frequency of reading newspaper/ magazine, frequency of listening to radio, and frequency of watching television. Some of these variables were recoded for meaningful and easy interpretation of results. They include mother's age at childbirth (less than 20, 20-29, 30-49), mother's education (no education, primary, secondary or higher), mother's religion (orthodox, protestants, other), birth order of child $(1,2-3,4$ or more), and number of ANC visits ( $0,1-3,4$ or more) (see Table 1).

\section{Statistical analysis}

Both descriptive and inferential analyses were conducted. We used descriptive statistics to describe the study sample and the prevalence of EIB across all the independent variables. After that, we built two logistic regression models and reported the results as crude and adjusted odds ratios (see Table 2). The model fitness specification was done with the Hosmer-Lemeshow test while multicollinearity was checked using the variance inflation factor (VIF), which showed no evidence of multicollinearity. We applied sample weight to take care of under and over sampling. We used the svy command to take care of the multi-stage sampling approach of the survey. We used STATA version 14.2 for MacOS to carry out the analyses, and statistical significance was set at $p<0.05$.

\section{Results}

\section{Prevalence of EIB}

Figure 1 shows the prevalence of EIB among women in Papua New Guinea. It was found that $60 \%$ of mothers breastfed their children within the first $1 \mathrm{~h}$ after delivery.

Sample characteristics and EIB behaviours among women in Papua New Guinea

Table 1 shows the background characteristics of the women. We found that $53.9 \%$ were aged 25-29.
Approximately $50.9 \%$ had primary level of education and $46.0 \%$ were Protestants. With wealth status, $24.9 \%$ were in the richer wealth category. Also, $7.4 \%$ were in rural areas. Similarly, $20.1 \%$ were in the Southern region. With EIB, generally, $60.0 \%$ of women in Papua New Guinea initiated breastfeeding within the first hour after delivery. Specifically, $60.4 \%$ of women aged 20-29, $60.6 \%$ of those with no education, $61.5 \%$ of Protestants, $62 \%$ of those in the middle wealth quintile, $60.7 \%$ of those in rural areas, $63.2 \%$ of those in southern region, and $63.6 \%$ of those who watched television less than once a week had the highest proportions of EIB (Table $1)$.

\section{Unadjusted and adjusted odds ratios of determinants of EIB in Papua New Guinea}

Women aged 20-29 [AOR $=1.583, \mathrm{CI}=1.147-2.185]$ and those aged $30+[\mathrm{AOR}=1.631, \mathrm{CI}=1.140-2.335]$ had higher odds of EIB, compared to those aged 15-19. In terms of region of residence, women from the Islands region had lower odds [AOR $=0.690, \mathrm{CI}=0.565-0.842]$ of EIB, compared to those in Southern region. In relation to mode of delivery, women who delivered through caesarean section (CS) had lower odds of EIB, compared to those who delivered via normal delivery $[\mathrm{AOR}=0.286$, $\mathrm{CI}=0.182-0.451]$. Relatedly, women who delivered in hospitals had lower odds of EIB [AOR $=0.752, \mathrm{CI}=$ 0.624-0.905], compared to those who delivered at home. Women who practiced skin-to-skin contact with the baby $[\mathrm{AOR}=1.640, \mathrm{CI}=1.385-1.942]$ had higher odds of EIB, compared to those who did not. Women who read newspaper or magazine at least once a week had lower odds of EIB [AOR $=0.781, \mathrm{CI}=0.619-0.986$ ], compared to those who do not read newspaper at all (Table 2).

\section{Discussion}

The Sustainable Development Goal (SDG) target 3.2 is a wakeup call for all countries to work in ending preventable deaths of newborns and reduce neonatal mortality to, at least, as low as 12 per 1000 live births and under-5 mortality to, at least, as low as 25 per 1000 live births by 2030 [34]. EIB has been identified by WHO as key to achieving this goal due to the associated health benefits such as increased ability to defend against infections, reduced risk of diarrhea, and increased survival rate of children [32]. It has, therefore, become important for health systems globally to understand some key factors that affect EIB. In the present study, we investigated the determinants of EIB in Papua New Guinea, given the high child mortality rate in the country [35], with the overall aim of producing findings that can serve as basis for policy interventions aimed at preventing child deaths 
Table 1 Sociodemographic characteristics of women and prevalence of early initiation of breastfeeding in Papua New Guinea, 2016-2018

\begin{tabular}{|c|c|c|c|c|}
\hline \multirow[t]{2}{*}{ Variable } & \multicolumn{2}{|c|}{ Sample $N=3198$} & \multirow{2}{*}{$\begin{array}{l}\text { EIB } \\
n\end{array}$} & \multirow{2}{*}{$\begin{array}{l}\text { EIB } \\
\%\end{array}$} \\
\hline & $\bar{N}$ & $\%$ & & \\
\hline \multicolumn{5}{|c|}{ Mother's age at childbirth } \\
\hline Less than 20 & 193 & 6.04 & 94 & 48.7 \\
\hline $20-29$ & 1725 & 53.94 & 1042 & 60.41 \\
\hline $30-49$ & 1280 & 40.03 & 778 & 60.78 \\
\hline \multicolumn{5}{|l|}{ Mother's education } \\
\hline No education & 635 & 19.86 & 385 & 60.63 \\
\hline Primary & 1628 & 50.91 & 978 & 60.07 \\
\hline Secondary or higher & 935 & 29.24 & 551 & 58.98 \\
\hline \multicolumn{5}{|l|}{ Mother's religion } \\
\hline Orthodox & 1045 & 32.68 & 625 & 59.81 \\
\hline Protestants & 1484 & 46.4 & 912 & 61.46 \\
\hline Other & 669 & 20.92 & 377 & 56.35 \\
\hline \multicolumn{5}{|l|}{ Wealth status } \\
\hline Poorest & 538 & 16.82 & 329 & 61.15 \\
\hline Poorer & 520 & 16.26 & 317 & 60.96 \\
\hline Middle & 628 & 19.64 & 390 & 62.1 \\
\hline Richer & 780 & 24.39 & 452 & 57.95 \\
\hline Richest & 732 & 22.89 & 426 & 58.2 \\
\hline \multicolumn{5}{|l|}{ Place of Residence } \\
\hline Urban & 722 & 2.58 & 410 & 56.79 \\
\hline Rural & 2476 & 77.42 & 1504 & 60.74 \\
\hline \multicolumn{5}{|l|}{ Region } \\
\hline Southern region & 961 & 30.05 & 607 & 63.16 \\
\hline Highlands region & 794 & 24.83 & 472 & 59.45 \\
\hline Momase region & 657 & 20.54 & 402 & 61.19 \\
\hline islands region & 786 & 24.58 & 433 & 55.09 \\
\hline \multicolumn{5}{|l|}{ Birth order of child } \\
\hline 1 & 759 & 23.73 & 420 & 55.34 \\
\hline $2-3$ & 1308 & 40.9 & 804 & 61.47 \\
\hline $4+$ & 1131 & 35.37 & 690 & 61.01 \\
\hline \multicolumn{5}{|l|}{ Number of ANC visits } \\
\hline No ANC & 759 & 23.73 & 474 & 62.45 \\
\hline $1-3$ & 776 & 24.27 & 466 & 60.05 \\
\hline $4+$ & 1663 & 52 & 974 & 58.57 \\
\hline \multicolumn{5}{|l|}{ Mode of delivery } \\
\hline Vaginal delivery & 3096 & 96.81 & 1887 & 60.95 \\
\hline Caesarean section & 102 & 3.19 & 27 & 26.47 \\
\hline \multicolumn{5}{|l|}{ Place of delivery } \\
\hline Health facility & 1992 & 62.29 & 1157 & 58.08 \\
\hline Home & 1206 & 37.71 & 757 & 62.77 \\
\hline \multicolumn{5}{|l|}{ Child size at birth } \\
\hline Small & 737 & 23.05 & 426 & 57.8 \\
\hline
\end{tabular}


Table 1 Sociodemographic characteristics of women and prevalence of early initiation of breastfeeding in Papua New Guinea, 2016-2018 (Continued)

\begin{tabular}{|c|c|c|c|c|}
\hline \multirow[t]{2}{*}{ Variable } & \multicolumn{2}{|c|}{ Sample $N=3198$} & \multirow{2}{*}{$\begin{array}{l}\text { EIB } \\
n\end{array}$} & \multirow{2}{*}{$\begin{array}{l}\text { EIB } \\
\%\end{array}$} \\
\hline & $N$ & $\%$ & & \\
\hline Average & 1208 & 37.77 & 742 & 61.42 \\
\hline Large & 1253 & 39.18 & 746 & 59.54 \\
\hline \multicolumn{5}{|l|}{ Skin-to-skin contact } \\
\hline No & 1542 & 48.22 & 862 & 55.9 \\
\hline Yes & 1656 & 51.78 & 1052 & 63.53 \\
\hline \multicolumn{5}{|c|}{ Frequency of reading newspaper/magazine } \\
\hline Not at all & 2084 & 65.17 & 1274 & 61.13 \\
\hline Less than once a week & 622 & 19.45 & 377 & 60.61 \\
\hline At least once a week & 492 & 15.38 & 263 & 53.46 \\
\hline \multicolumn{5}{|c|}{ Frequency of listening to radio } \\
\hline Not at all & 2072 & 64.79 & 1258 & 60.71 \\
\hline Less than once a week & 582 & 18.2 & 344 & 59.11 \\
\hline at least once a week & 544 & 17.01 & 312 & 57.35 \\
\hline \multicolumn{5}{|c|}{ Frequency of watching Television } \\
\hline Not at all & 2480 & 77.55 & 1494 & 60.24 \\
\hline Less than once a week & 305 & 9.54 & 194 & 63.61 \\
\hline At least once a week & 413 & 12.91 & 226 & 54.72 \\
\hline
\end{tabular}

in the country. This section discusses key findings of the study.

The results revealed that $60 \%$ of mothers in Papua New Guinea breastfed their children within the first hour after delivery, which is similar to what was reported in Bangladesh (51\%) [16] and Zimbabwe (58.3\%) [30]. This result is, however, lower than the prevalence in many other low- and middle-income countries. For example, 74.3-83.7\% was recorded in Ethiopia [17, 19, 36, 37], $76.9 \%$ in Malawi [38], $77.74 \%$ in Mozambique, $81.51 \%$ in Rwanda [33], and $68.6 \%$ in Uganda [39]. On the other hand, the prevalence is higher than what was reported in India (36.4\%) [40] and 24\% in Pakistan [41]. The possible reason for the differences in study findings might be differences in geographical locations/settings, the time differences the studies were conducted and socio-cultural practices as well as differences in the rate of caesarean deliveries $[18,23]$. The relatively low EIB recorded in the present study could be explained in the context of some socio-cultural beliefs in the country. For instance, mothers in Papua New Guinea believe that colostrum is dirty and unclean and thus can harm their babies [8]. In the light of this finding, it is, therefore, imperative for the government to implement policies to educate women on the importance of colostrum to their babies. Such policies can help rectify this misconception held by the mothers and boost early initiation of breastfeeding in the country. Thus, the development of the UNICEF-Papua New Guinea Country Program 2018-2022, which aims to build capacity of the most deprived provinces in the country to improve nutritionfocused interventions [42], is in the right direction.

The results showed that mothers who were more than 20 years of age had higher odds of EIB, compared to those aged 19 and below who would probably be having their 1st birth. Duodu et al. [32] have reported similar findings from their study in Ghana, which suggests that infants who were not firstborns had higher likelihood of achieving EIB. This significant finding from the study is also in support of findings in Sri Lanka [43], India [44], Pakistan [45], Namibia [46], and Ethiopia [19]. The reason could be that mothers who are more than 20 years old at birth could likely be having their 2nd birth and might have already been exposed to benefits of EIB through postnatal care for their first child and antenatal care. As such, they will be much conscious and knowledgeable about reaping the benefits associated with EIB. In some situations, younger mothers and those going through delivery for the first time often become tired, exhausted, and may need time to recover from delivery complications with the potential of missing EIB. Evidently, an earlier study in Papua New Guinea reported good knowledge and positive attitudes to breastfeeding among older women [47]. It is therefore 
Table 2 Crude (unadjusted) and adjusted odds ratios of determinants of early initiation of breastfeeding in Papua New Guinea, 2016-2018

\begin{tabular}{|c|c|c|}
\hline \multirow[t]{2}{*}{ Variables } & \multicolumn{2}{|l|}{ EIB } \\
\hline & COR[95\%Cl] & AOR[95\%Cl] \\
\hline \multicolumn{3}{|c|}{ Mother's age at childbirth } \\
\hline Less than 20 & Ref & Ref \\
\hline $20-29$ & $1.607^{* *}[1.192,2.165]$ & $1.583^{* *}[1.147,2.185]$ \\
\hline $30+$ & $1.632^{* *}[1.205,2.212]$ & $1.631^{* *}[1.140,2.335]$ \\
\hline \multicolumn{3}{|l|}{ Mother's education } \\
\hline No education & Ref & \\
\hline Primary & $0.977[0.810,1.179]$ & - \\
\hline Secondary or higher & $0.932[0.758,1.145]$ & - \\
\hline \multicolumn{3}{|l|}{ Mother's religion } \\
\hline Orthodox & Ref & \\
\hline Protestants & $1.071[0.911,1.260]$ & - \\
\hline Other & $0.868[0.713,1.056]$ & - \\
\hline \multicolumn{3}{|l|}{ Wealth } \\
\hline Poorest & Ref & \\
\hline Poorer & $0.992[0.775,1.270]$ & - \\
\hline Middle & $1.041[0.821,1.319]$ & - \\
\hline Richer & $0.875[0.700,1.095]$ & - \\
\hline Richest & $0.884[0.705,1.110]$ & - \\
\hline \multicolumn{3}{|l|}{ Residence } \\
\hline Urban & Ref & \\
\hline Rural & $1.177[0.995,1.393]$ & \\
\hline \multicolumn{3}{|l|}{ Region } \\
\hline Southern region & Ref & Ref \\
\hline Highlands region & $0.855[0.705,1.037]$ & $0.87[0.713,1.060]$ \\
\hline Momase region & $0.919[0.749,1.128]$ & $0.869[0.703,1.075]$ \\
\hline Islands region & $0.715^{* * *}[0.590,0.867]$ & $0.690^{* * *}[0.565,0.842]$ \\
\hline \multicolumn{3}{|l|}{ Birth order of child } \\
\hline 1 & Ref & Ref \\
\hline $2-3$ & $1.288^{* *}[1.074,1.544]$ & $1.146[0.940,1.398]$ \\
\hline $4+$ & $1.263^{*}[1.048,1.522]$ & $1.084[0.853,1.378]$ \\
\hline \multicolumn{3}{|l|}{ Number of ANC visits } \\
\hline No ANC & Ref & Ref \\
\hline $1-3$ & $0.904[0.736,1.110]$ & - \\
\hline $4+$ & $0.85[0.713,1.014]$ & - \\
\hline \multicolumn{3}{|l|}{ Mode of delivery } \\
\hline Vaginal delivery & Ref & Ref \\
\hline Caesarean section & $0.231^{* * *}[0.148,0.360]$ & $0.286^{* * *}[0.182,0.451]$ \\
\hline \multicolumn{3}{|l|}{ Place of delivery } \\
\hline Health facility & $0.822^{* *}[0.710,0.952]$ & $0.752^{* *}[0.624,0.905]$ \\
\hline Home & Ref & Ref \\
\hline \multicolumn{3}{|l|}{ Child size at birth } \\
\hline Small & Ref & Ref \\
\hline
\end{tabular}


Table 2 Crude (unadjusted) and adjusted odds ratios of determinants of early initiation of breastfeeding in Papua New Guinea, 2016-2018 (Continued)

\begin{tabular}{|c|c|c|}
\hline \multirow[t]{2}{*}{ Variables } & \multicolumn{2}{|l|}{ EIB } \\
\hline & COR[95\%Cl] & AOR[95\%Cl] \\
\hline Average & $1.162[0.965,1.401]$ & - \\
\hline Large & $1.074[0.893,1.292]$ & - \\
\hline \multicolumn{3}{|l|}{ Skin-to-skin contact } \\
\hline No & Ref & Ref \\
\hline Yes & $1.374^{* * *}[1.192,1.583]$ & $1.640^{* * *}[1.385,1.942]$ \\
\hline \multicolumn{3}{|c|}{ Frequency of reading newspaper/magazine } \\
\hline Not at all & Ref & Ref \\
\hline Less than once a week & $0.978[0.814,1.175]$ & $0.994[0.812,1.218]$ \\
\hline At least once a week & $0.730^{* *}[0.599,0.890]$ & $0.781^{*}[0.619,0.986]$ \\
\hline \multicolumn{3}{|l|}{ Frequency of watching TV } \\
\hline Not at all & Ref & Ref \\
\hline Less than once a week & $1.153[0.901,1.476]$ & $1.141[0.875,1.488]$ \\
\hline At least once a week & $0.798 *[0.647,0.984]$ & $0.885[0.692,1.131]$ \\
\hline \multicolumn{3}{|c|}{ Frequency of listening to radio } \\
\hline Not at all & Ref & \\
\hline Less than once a week & $0.935[0.775,1.128]$ & - \\
\hline At least once a week & $0.87[0.719,1.054]$ & - \\
\hline N & & 3198 \\
\hline pseudo $R^{2}$ & & 0.028 \\
\hline
\end{tabular}

${ }^{*} p<0.05,{ }^{* *} p<0.01,{ }^{* * *} p<0.001$, Ref reference, COR Crude Odds Ratio, AOR Adjusted Odds Ratio Exponentiated coefficients; $95 \%$ confidence intervals in brackets

Source: PDHS (2016-2018)

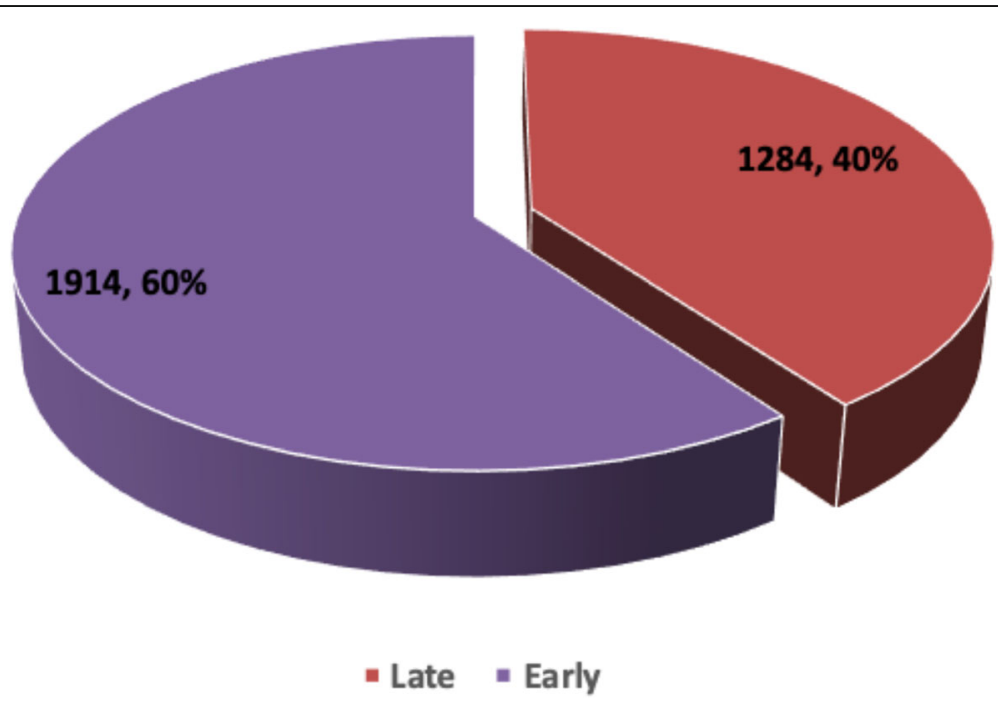

Fig. 1 Prevalence of Early Initiation of Breastfeeding in Papua New Guinea, 2016-2018. Source: PDHS (2016-2018) 
important for health workers to educate mothers on the importance of EIB especially younger mothers during ANC and PNC.

There was also a significantly strong association between mode of delivery, place of delivery, and EIB in Papua New Guinea. The mothers who delivered through C-Section had lower odds of EIB, compared to those who delivered via normal vaginal delivery. Relatedly, women who delivered in a hospital had lower odds of EIB, compared to those who delivered at home. This finding is consistent with many findings in low- and middle-income countries such as Ghana [32], Kenya [48], Nepal [49], Zimbabwe [50], and Nigeria [23]. The reasons could be that, after a mother goes through CS delivery, she needs time to gain consciousness from the anesthesia and any complications resulting from the process, thereby putting them at risk of losing EIB [51]. For example, a study by Scott el al [52]. has revealed that delivery by CS-section has physiologic effect on lactogenesis, which results in delays in lactation, which prevents EIB. Some of the barriers posed by CS could be lengthy post-delivery hospital stays, prolonged motherchild separation, delayed skin-to-skin contact, and maternal endocrinological diseases [23]. Also, all CS are conducted in the health facility and this could explain why it is reported in the study that mothers delivering in the health facility had lower prospects of EIB. In Bangladesh, for instance, it is reported that C-Section, possibly, is another reason for lower EIB among mothers who delivered at health facilities than at home, as over $60 \%$ of childbirths at health facilities are conducted by $\mathrm{C}$-section [53]. However, this finding is in sharp contrast with what has been reported by Adhikari et al. [54] in Nepal, who found that health facility delivery had a positive influence on EIB. Specifically, Adhikari et al. [54] noted that children born in health facilities were more likely to be breastfed within one hour, compared to those born at home. Further studies could explore health facility delivery, caesarean section and EIB.

We also observed that women who practiced skin-toskin contact with the baby had higher odds of EIB, compared to those who did not. This finding is in support of findings from a quasi-experimental study in Iraq by Safari et al. [55] which reported that mothers who had skin-toskin contact with their newborns were more likely to practice EIB. Furthermore, studies conducted in USA by Moore and Anderson [56], in Iran by Khadivzadeh and Karimi [57], and in Pakistan by Mahmood et al. [58] have all reported affirmatively that mothers are more likely to practice EIB when they have skin-to-skin contact with their newborns. The reason could be that early skin-toskin contact results in higher breastfeeding self-efficacy in mothers and gives mothers confidence in their ability to breastfeed their newborns $[58,59]$.
Moreover, the study revealed an inverse relationship between mothers reading newspaper/magazine at least once a week and EIB in Papua New Guinea, which is similar to a previous study in Ethiopia on the association between exposure to mass media and EIB [60]. Specifically, it was noted that women who read newspaper at least once a week had lower odds of EIB. This finding, however, contradicts findings from a study conducted in Ghana by Duodu et al. [32] which reported no statistical significance between watching television, listening to radio, and EIB. The association between exposure to newspaper and EIB foregrounds the need for further studies to unravel the nuances since newspaper reading is reducing due to the growth of the internet and the provisions of digital information sources [61].

Again, as shown in previous studies in Ghana [32], Kenya [48], Nepal [49], Nigeria [23], and Saudi Arabia [24], we observed that region of residence is associated with EIB, with women from the Islands region having lower odds of EIB compared to those in Southern region. The Southern region of Papua New Guinea is predominantly developed. It contains the city of Port Moresby, which is the capital of the country and the center for major businesses. On the other hand, the Islands region is less developed and contains least densely populated areas in the country [62-64]. A study by Woldeamanuel [65] reported that mothers in urban or developed areas in Ethiopia are 29\% more likely to practice EIB than mothers in the less developed areas. Similar findings have been reported by Bbaale [66] in Uganda, Yahya and Adebayo [67] in Nigeria, and Victor et al. [68] in Tanzania. The regional disparities of EIB in Papua New Guinea could be as a result of the disparities in the allocation of developmental projects and health amenities across the regions in the country. For instance, residents in the southern region have more and easy access to maternal health information, education, and services as compared to their counterparts in the Islands region, which could lead to high EIB [64]. This finding highlights the need for policies and programs aimed at improving EIB to pay attention to cross-regional variations in EIB. Specifically, such policies need to focus attention on women from deprived regions of Papua New Guinea.

\section{Strength and limitations}

The major strength of this study is the use of a large nationally representative sample which adheres to rigorous methodology and the use of validated instruments. This makes the findings generalizable to childbearing women in Papua New Guinea. Nonetheless, there is the possibility of recall-biased responses. With regard to the breastfeeding initiation, time after birth might introduce error in reporting by mothers. However, since giving birth is 
one of the memorable events for mothers, we assume such error would be minimal. The study employed cross-sectional design and, therefore, causality of the findings cannot be claimed. We also acknowledge that the determinants discussed in the paper are not new in the global context, they are rather offering support for earlier studies.

\section{Conclusion}

The prevalence of EIB in Papua New Guinea was relatively high (60\%). The factors associated with EIB are age of the women, region of residence, mode of delivery, place of delivery, practice of skin-to-skin contact with the baby. To scale up EIB in Papua New Guinea, these factors ought to be considered in the implementation of policies and strengthening of existing ones. There is the need for health professionals to educate mothers on the importance of EIB. Further studies could explore place of delivery, type of delivery and EIB.

\section{Abbreviations}

EIB: Early Initiation of Breastfeeding; COR: Crude Odds Ratio;" AOR: Adjusted Odds Ratio; Cl: Confidence Interval; PDHS: Papua New Guinea Demographic and Health Survey (PDHS); VIF: Variance Inflation Factor

\section{Acknowledgements}

We are grateful to MEASURE DHS project for giving us free access to the original data.

\section{Authors' contributions}

AS conceived the study. AS analysed the data. AS, BOA, EA, LKD, JKT, EKA, TS and SY drafted the manuscript and revised the manuscript critically for important intellectual content. All the authors have read and approved the final version for submission.

\section{Authors' information}

Department of Population and Health, University of Cape Coast, Cape Coast, Ghana (AS;JKT; TS;LKD); College of Public Health, Medical and Veterinary Sciences, James Cook University, Townsville, Queensland, Australia (AS);The Australian Centre for Public and Population Health Research (ACPPHR), Faculty of Health, University of Technology Sydney, Australia (BOA); Department of English, University of Cape Coast, Cape Coast, Ghana (EA) School of International Development and Global Studies, University of Ottawa, Ottawa, Canada (SY);The George Institute for Global Health, The University of Oxford, Oxford, United Kingdom (SY).

\section{Funding}

The study did not receive any funding.

\section{Availability of data and materials}

The dataset can be accessed via this link: https://dhsprogram.com/data/ dataset/Papua-New-Guinea_Standard-DHS_2017.cfm?flag=0

\section{Ethics approval and consent to participate}

The 2016-2018 PDHS report indicated that ethical approval was granted by the ICF Institutional Review Board [31]. Both written and verbal informed consent were also sought from all the participants during the data collection exercise. We requested for the dataset on 10th March, 2020.

\section{Consent for publication}

Not applicable.

\section{Competing interests}

The authors declare that they have no competing interests.

\section{Author details}

${ }^{1}$ Department of Population and Health, University of Cape Coast, Cape Coast, Ghana. ${ }^{2}$ College of Public Health, Medical and Veterinary Sciences, James Cook University, Townsville, Queensland, Australia. ${ }^{3}$ School of Public Health, Faculty of Health, University of Technology Sydney, Sydney, Australia. ${ }^{4}$ Department of English, University of Cape Coast, Cape Coast, Ghana. ${ }^{5}$ School of International Development and Global Studies, University of Ottawa, Ottawa, Canada. ${ }^{6}$ The George Institute for Global Health, The University of Oxford, Oxford, UK.

Received: 20 July 2020 Accepted: 13 November 2020

Published online: 23 November 2020

\section{References}

1. Hansen K. Breastfeeding: a smart investment in people and in economies. Lancet. 2016;387(10017):416.

2. Kramer MS, Kakuma R. Optimal duration of exclusive breastfeeding. Cochrane Database Syst Rev. 2012;81-85.

3. United Nations Children's Fund (UNICEF). State of the World's Children 2014: Every child counts. New York: United Nations Children's Fund (UNICEF); 2014.

4. Lamberti LM, Walker CL, Noiman A, Victora C, Black RE. Breastfeeding and the risk for diarrhea morbidity and mortality. BMC Public Health. 2011;11(3):1-2.

5. Debes AK, Kohli A, Walker N, Edmond K, Mullany LC. Time to initiation of breastfeeding and neonatal mortality and morbidity: a systematic review. BMC Public Health. 2013;13(S3):S19.

6. Lamberti LM, Zakarija-Grković I, Walker CL, Theodoratou E, Nair H, Campbell $H$, Black RE. Breastfeeding for reducing the risk of pneumonia morbidity and mortality in children under two: a systematic literature review and metaanalysis. BMC Public Health. 2013;13(S3):S18.

7. Himani BK, Kumar P. Effect of initiation of breastfeeding within one hour of the delivery on" maternal-infant bonding. Nursing and Midwifery Research Journal. 2011 Jul;7(3).

8. Kuzma J. Knowledge, attitude and practice related to infant feeding among women in rural Papua New Guinea: a descriptive, mixed method study. Int Breastfeed J. 2013;8(1):1-5.

9. NEOVITA Study Group. Timing of initiation, patterns of breastfeeding, and infant survival: prospective analysis of pooled data from three randomised trials. Lancet Glob Health. 2016;4(4):e266-75.

10. World Health Organisation and UNICEF. Capture the moment - Early initiation of breastfeeding: the best start for every newborn. 2018.

11. Taqi I. Global breastfeeding advocacy initiative. Breastfeed Med. 2014;9(7): 355-7.

12. Mangasaryan N, Martin L, Brownlee A, Ogunlade A, Rudert C, Cai X. Breastfeeding promotion, support and protection: review of six country programmes. Nutrients. 2012;4(8):990-1014.

13. UNICEF. From the first hours of life. 2016.

14. Goris J, Zomerdijk N, Temple V. Nutritional status and dietary diversity of Kamea in gulf province, Papua new guineas. Asia Pac J Clin Nutr. 2017;26(4): 665-70.

15. Karim F, Billah SM, Chowdhury MA, Zaka N, Manu A, Arifeen SE, Khan AN. Initiation of breastfeeding within one hour of birth and its determinants among normal vaginal deliveries at primary and secondary health facilities in Bangladesh: a case-observation study. PLoS One. 2018;13(8):e0202508.

16. Karim F, Khan AN, Tasnim F, Chowdhury MA, Billah SM, Karim T, Arifeen SE, Garnett SP. Prevalence and determinants of initiation of breastfeeding within one hour of birth: an analysis of the Bangladesh demographic and health survey, 2014. PLoS One. 2019;14(7):e0220224.

17. Abie BM, Goshu YA. Early initiation of breastfeeding and colostrum feeding among mothers of children aged less than 24 months in Debre Tabor, Northwest Ethiopia: a cross-sectional study. BMC Res Notes. 2019;12(1):65.

18. Gebremeskel SG, Gebru TT, Gebrehiwot BG, Meles HN, Tafere BB, Gebreslassie GW, Welay FT, Mengesha MB, Weldegeorges DA. Early initiation of breastfeeding and associated factors among mothers of aged less than 12 months children in rural eastern zone, Tigray, Ethiopia: cross-sectional study. BMC Res Notes. 2019;12(1):671.

19. John JR, Mistry SK, Kebede G, Manohar N, Arora A. Determinants of early initiation of breastfeeding in Ethiopia: a population-based study using the 2016 demographic and health survey data. BMC Pregnancy Child. 2019; 19(1):69. 
20. Tilahun G, Degu G, Azale T, Tigabu A. Prevalence and associated factors of timely initiation of breastfeeding among mothers at Debre Berhan town, Ethiopia: a cross-sectional study. Int Breastfeed J. 2016;11(1):27.

21. Acharya $P$, Khanal $V$. The effect of mother's educational status on early initiation of breastfeeding: further analysis of three consecutive Nepal demographic and health surveys. BMC Public Health. 2015;15(1):1069.

22. Horii N, Allman J, Martin-Prével Y, Waltisperger D. Determinants of early initiation of breastfeeding in rural Niger: cross-sectional study of community based child healthcare promotion. Int Breastfeed J. 2017;12(1):41.

23. Berde AS, Yalcin SS. Determinants of early initiation of breastfeeding in Nigeria: a population-based study using the 2013 demograhic and health survey data. BMC Pregnancy Child. 2016;16(1):32.

24. Alzaheb RA. Factors associated with the initiation of breastfeeding within the first 48 hours of life in Tabuk, Saudi Arabia. Int Breastfeed J. 2016;11(1):21.

25. Azzeh FS, Alazzeh AY, Hijazi HH, Wazzan HY, Jawharji MT, Jazar AS, Filimban AM, Alshamrani AS, Labani MS, Hasanain TA, Obeidat AA. Factors associated with not breastfeeding and delaying the early initiation of breastfeeding in Mecca region, Saudi. Arabia Children. 2018;5(1):8.

26. Exavery A, Kanté AM, Hingora A, Phillips JF. Determinants of early initiation of breastfeeding in rural Tanzania. Int Breastfeed J. 2015;10(1):27.

27. Mukunya D, Tumwine JK, Nankabirwa V, Ndeezi G, Odongo I, Tumuhamye J, Tongun JB, Kizito S, Napyo A, Achora V, Odongkara B. Factors associated with delayed initiation of breastfeeding: a survey in northern Uganda. Glob Health Action. 2017;10(1):1410975.

28. Mukora-Mutseyekwa F, Gunguwo H, Mandigo RG, Mundagowa P. Predictors of early initiation of breastfeeding among Zimbabwean women: secondary analysis of ZDHS 2015. Matern Health Neonatol Perinatol. 2019;5(1):2.

29. Yaya S, Uthman OA, Ekholuenetale M, Bishwajit G, Adjiwanou V. Effects of birth spacing on adverse childhood health outcomes: evidence from 34 countries in sub-Saharan Africa. J Matern Fetal Neonatal Med 2019 8:1-8.

30. Yaya S, Bishwajit G, Shibre G, Buh A. Timely initiation of breastfeeding in Zimbabwe: evidence from the demographic and health surveys 1994-2015. Int Breastfeed J. 2020;15(1):1-7.

31. National Statistical Office (NSO) [Papua New Guinea] (PNG) and ICF. Papua New Guinea Demographic and Health Survey 2016-2018. National Report (2019). Port Moresby: National Statistical Office.

32. Duodu PA, Duah HO, Dzomeku VM, Boamah Mensah AB, Aboagye Mensah J, Darkwah E, Agbadi P. Consistency of the determinants of early initiation of breastfeeding in Ghana: insights from four demographic and health survey datasets. Int Health. 2020:17.

33. Issaka Al, Agho KE, Renzaho AM. Prevalence of key breastfeeding indicators in 29 sub-Saharan African countries: a meta-analysis of demographic and health surveys (2010-2015). BMJ Open. 2017;7(10):1-10.

34. United Nations. Sustainable development goals. 2015.

35. Duke T, Kado JH, Auto J, Amini J, Gilbert K. Closing the gaps in child health in the $P$ acific: an achievable goal in the next 20 years. J Paediatr Child Health. 2015;51(1):54-60

36. Beyene MG, Geda NR, Habtewold TD, Assen ZM. Early initiation of breastfeeding among mothers of children under the age of 24 months in southern Ethiopia. Int Breastfeed J 2016;12(1):1

37. Tewabe T. Timely initiation of breastfeeding and associated factors among mothers in Motta town, east Gojjam zone, Amhara regional state, Ethiopia, 2015: a cross-sectional study. BMC Pregnancy Child. 2016;16(1):314.

38. Nkoka O, Ntenda PA, Kanje V, Milanzi EB, Arora A. Determinants of timely initiation of breast milk and exclusive breastfeeding in Malawi: a populationbased cross-sectional study. Int Breastfeed J. 2019;14(1):37.

39. Kalisa R, Malande O, Nankunda J, Tumwine JK. Magnitude and factors associated with delayed initiation of breastfeeding among mothers who deliver in Mulago hospital, Uganda. Afr Health Sci. 2015;15(4):1130-5.

40. Patel A, Banerjee A, Kaletwad A. Factors associated with prelacteal feeding and timely initiation of breastfeeding in hospital-delivered infants in India. J Hum Lact. 2013;29(4):572-8.

41. Patel A, Bucher S, Pusdekar Y, Esamai F, Krebs NF, Goudar SS, Chomba E, Garces A, Pasha O, Saleem S, Kodkany BS. Rates and determinants of early initiation of breastfeeding and exclusive breast feeding at 42 days postnatal in six low and middle-income countries: a prospective cohort study. Reprod Health. 2015;12(S2):S10.

42. UNICEF-PNG. 2017. Programme Strategic Notes - Nutrition. Retrieved from http://files.unicef.org/transparency/documents/PNG\%20SN\%20NUTRITION\%2 023Feb\%20Clean.pdf.
43. Senarath U, Siriwardena I, Godakandage SS, Jayawickrama H, Fernando DN, Dibley MJ. Determinants of breastfeeding practices: an analysis of the Sri Lanka demographic and health survey 2006-2007. Matern Child Nutr. 2012; 8(3):315-29.

44. Athavale AV, Athavale SA, Deshpande SG, Zodpey SP, Sangole S. Initiation of breast-feeding by urban women. Health Popul Perspect Issues. 2004; 27(2):117-25.

45. Hazir T, Akram DS, Nisar YB, Kazmi N, Agho KE, Abbasi S, Khan AM, Dibley MJ. Determinants of suboptimal breast-feeding practices in Pakistan. Public Health Nutr. 2013;16(4):659-72.

46. Ndirangu MN, Gatimu SM, Mwinyi HM, Kibiwott DC. Trends and factors associated with early initiation of breastfeeding in Namibia: analysis of the demographic and health surveys 2000-2013. BMC Pregnancy Child. 2018; 18(1):171.

47. Vijayalakshmi P, Susheela T, Mythili D. Knowledge, attitudes, and breast feeding practices of postnatal mothers: a cross sectional survey. Int J Health Sci. 2015;9(4):364.

48. Matanda DJ, Mittelmark MB, Urke HB, Amugsi DA. Reliability of demographic and socioeconomic variables in predicting early initiation of breastfeeding: a replication analysis using the Kenya demographic and health survey data. BMJ Open. 2014;4(6):1-13.

49. Khanal V, Scott JA, Lee AH, Karkee R, Binns CW. Factors associated with early initiation of breastfeeding in Western Nepal. Int J Environ Res Public Health. 2015;12(8):9562-74.

50. Mbakaya BC, Mukora-Mutseyekwa F, Chideme-Munodawafa A, Mwale CM, Letcher MM. Factors associated with development of typhoid fever at Kaziwiziwi coal mining area in Rumphi District, Malawi: A Retrospective Case Control Study Eur Sci J 2015;11(33):214-23.

51. Hobbs AJ, Mannion CA, McDonald SW, et al. The impact of caesarean section on breastfeeding initiation, duration and difficulties in the first four months postpartum. BMC Pregnancy Child. 2016;16:90 https://doi.org/10. 1186/s12884-016-0876-1.

52. Scott JA, Binns CW, Oddy WH.(2007). Predictors of delayed onset of lactation. Matern Child Nutr 2007;3(3):186-193.

53. National Institute of Population Research and Training (NIPORT), Mitra and Associates, and ICF International. Bangladesh Demographic and Health Survey 2014. Dhaka, Bangladesh, and Rockville, Maryland, USA: NIPORT, Mitra and Associates, and ICF International; 2016.

54. Adhikari M, Khanal V, Karkee R, Gavidia T. Factors associated with early initiation of breastfeeding among Nepalese mothers: further analysis of Nepal demographic and health survey, 2011. Int Breastfeed J. 2014;9(1):21.

55. Safari K, Saeed AA, Hasan SS, Moghaddam-Banaem L. The effect of mother and new-born early skin-to-skin contact on initiation of breastfeeding, newborn temperature and duration of third stage of labor. Int Breastfeed J. 2018;13(1):32.

56. Moore ER, Anderson GC. Randomized controlled trial of very early motherinfant skin-to-skin contact and breastfeeding status. J Midwifery Women's Health. 2007;52(2):116-25.

57. Khadivzadeh T, Aghdas K. The effects of post-birth mother-infant skin to skin contact on first breastfeeding. Iranian Journal of Nursing and Midwifery Reasearch. 2009:14(3):111-6.

58. Mahmood I, Jamal M, Khan N. Effect of mother-infant early skin-to-skin contact on breastfeeding status: a randomized controlled trial. J Coll Physicians Surg Pak. 2011;21(10):601-5.

59. Aghdas K, Talat K, Sepideh B. Effect of immediate and continuous motherinfant skin-to-skin contact on breastfeeding self-efficacy of primiparous women: a randomised control trial. Women Birth. 2014;27(1):37-40.

60. Hailemariam TW, Adeba E, Sufa A. Predictors of early breastfeeding initiation among mothers of children under 24 months of age in rural part of West Ethiopia. BMC Public Health. 2015;15(1):1076.

61. Papua New Guinea Internet use. Source: https://www.theglobaleconomy. com/Papua-New-Guinea/Internet_users/ Accessed on 5/11/2020.

62. Bauze AE, Tran LN, Nguyen KH, Firth S, Jimenez-Soto E, Dwyer-Lindgren L, et al. Equity and geography: the case of child mortality in Papua New Guinea. Plos One. 2012;7(5):e37861.

63. Jones P. Pacific urbanisation and the rise of informal settlements: trends and implications from Port Moresby. Urban Policy Res. 2012;30(2):145-60.

64. Kassens AL, van der Meulen Rodgers Y. Health and distance to healthcare in Papua New Guinea. In: Disease, human health, and regional growth and development in Asia. Singapore: Springer; 2019. p. 203-29. 
65. Woldeamanuel BT. Trends and factors associated to early initiation of breastfeeding, exclusive breastfeeding and duration of breastfeeding in Ethiopia: evidence from the Ethiopia demographic and health survey 2016. Int Breastfeed J. 2020;15(1):3 https://doi.org/10.1186/s13006-019-0248-3.

66. Bbaale E. Determinants of early initiation, exclusiveness, and duration of breastfeeding in Uganda. J Health Popul Nutr. 2014;32(2):249.

67. Babatunde Yahya W, Adebayo SB. Modelling the trend and determinants of breastfeeding initiation in Nigeria. Child Dev Res 2013;2013.

68. Victor R, Baines SK, Agho KE, Dibley MJ. Determinants of breastfeeding indicators among children less than 24 months of age in Tanzania: a secondary analysis of the 2010 Tanzania demographic and health survey. BMJ Open. 2013;3(1):1-8.

\section{Publisher's Note}

Springer Nature remains neutral with regard to jurisdictional claims in published maps and institutional affiliations.

- fast, convenient online submission

- thorough peer review by experienced researchers in your field

- rapid publication on acceptance

- support for research data, including large and complex data types

- gold Open Access which fosters wider collaboration and increased citations

- maximum visibility for your research: over $100 \mathrm{M}$ website views per year

At $\mathrm{BMC}$, research is always in progress. 